NASA/TM-2007-214824

\title{
Cryogenic Technology Development for Exploration Missions
}

David J. Chato

Glenn Research Center, Cleveland, Ohio 


\section{NASA STI Program . . . in Profile}

Since its founding, NASA has been dedicated to the advancement of aeronautics and space science. The NASA Scientific and Technical Information (STI) program plays a key part in helping NASA maintain this important role.

The NASA STI Program operates under the auspices of the Agency Chief Information Officer. It collects, organizes, provides for archiving, and disseminates NASA's STI. The NASA STI program provides access to the NASA Aeronautics and Space Database and its public interface, the NASA Technical Reports Server, thus providing one of the largest collections of aeronautical and space science STI in the world. Results are published in both non-NASA channels and by NASA in the NASA STI Report Series, which includes the following report types:

- TECHNICAL PUBLICATION. Reports of completed research or a major significant phase of research that present the results of NASA programs and include extensive data or theoretical analysis. Includes compilations of significant scientific and technical data and information deemed to be of continuing reference value. NASA counterpart of peer-reviewed formal professional papers but has less stringent limitations on manuscript length and extent of graphic presentations.

- TECHNICAL MEMORANDUM. Scientific and technical findings that are preliminary or of specialized interest, e.g., quick release reports, working papers, and bibliographies that contain minimal annotation. Does not contain extensive analysis.

- CONTRACTOR REPORT. Scientific and technical findings by NASA-sponsored contractors and grantees.
- CONFERENCE PUBLICATION. Collected papers from scientific and technical conferences, symposia, seminars, or other meetings sponsored or cosponsored by NASA.

- SPECIAL PUBLICATION. Scientific, technical, or historical information from NASA programs, projects, and missions, often concerned with subjects having substantial public interest.

- TECHNICAL TRANSLATION. Englishlanguage translations of foreign scientific and technical material pertinent to NASA's mission.

Specialized services also include creating custom thesauri, building customized databases, organizing and publishing research results.

For more information about the NASA STI program, see the following:

- Access the NASA STI program home page at http://www.sti.nasa.gov

- E-mail your question via the Internet to help@sti.nasa.gov

- Fax your question to the NASA STI Help Desk at 301-621-0134

- Telephone the NASA STI Help Desk at 301-621-0390

- Write to: NASA Center for AeroSpace Information (CASI) 7115 Standard Drive Hanover, MD 21076-1320 
NASA/TM-2007-214824

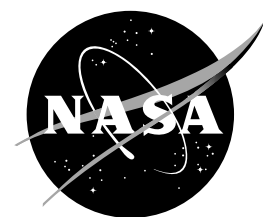

\section{Cryogenic Technology Development for Exploration Missions}

David J. Chato

Glenn Research Center, Cleveland, Ohio

Prepared for the

45th AIAA Aerospace Sciences Meeting and Exhibit

sponsored by the American Institute of Aeronautics and Astronautics

Reno, Nevada, January 8-11, 2007

National Aeronautics and

Space Administration

Glenn Research Center

Cleveland, Ohio 44135 
Trade names and trademarks are used in this report for identification only. Their usage does not constitute an official endorsement, either expressed or implied, by the National Aeronautics and Space Administration.

Level of Review: This material has been technically reviewed by technical management.

Available from

NASA Center for Aerospace Information 7115 Standard Drive

Hanover, MD 21076-1320
National Technical Information Service 5285 Port Royal Road Springfield, VA 22161 


\title{
Cryogenic Technology Development for Exploration Missions
}

\author{
David J. Chato \\ National Aeronautics and Space Administration \\ Glenn Research Center \\ Cleveland, Ohio 44135
}

\begin{abstract}
This paper reports the status and findings of different cryogenic technology research projects in support of the President's Vision for Space Exploration. The exploration systems architecture study is reviewed for cryogenic fluid management needs. It is shown that the exploration architecture is reliant on the cryogenic propellants of liquid hydrogen, liquid oxygen and liquid methane. Needs identified include: the key technologies of liquid acquisition devices, passive thermal and pressure control, low gravity mass gauging, prototype pressure vessel demonstration, active thermal control; as well as feed system testing, and Cryogenic Fluid Management integrated system demonstration. Then five NASA technology projects are reviewed to show how these needs are being addressed by technology research. Projects reviewed include: In-Space Cryogenic Propellant Depot; Experimentation for the Maturation of Deep Space Cryogenic Refueling Technology; Cryogenic Propellant Operations Demonstrator; Zero Boil-Off Technology Experiment; and Propulsion and Cryogenic Advanced Development. Advances are found in the areas of liquid acquisition of liquid oxygen, mass gauging of liquid oxygen via radio frequency techniques, computational modeling of thermal and pressure control, broad area cooling thermal control strategies, flight experiments for resolving low gravity issues of cryogenic fluid management. Promising results are also seen for Joule-Thomson pressure control devices in liquid oxygen and liquid methane and liquid acquisition of methane, although these findings are still preliminary.
\end{abstract}

\section{Introduction}

The President's Vision for Space Exploration (VSE) (ref. 1) articulated a need for future space technologies. One of its goals is to develop the innovative technologies, knowledge, and infrastructures both to explore and to support decisions about the destinations for human exploration. It is the author's belief that one of the technologies that will be key is Cryogenic Fluid Management (CFM). The Vision for Space Exploration also identifies in its goals developing and demonstrating propulsion systems required to support more distant, more capable, and longer duration human and robotic exploration. Achieving this goal will require many cryogenic propulsion system elements that need to operate in Low Earth Orbit (LEO) and lunar orbits for long periods, as well as during transit to Mars or other destinations. CFM technology is essential to implementing the propulsion systems required for carrying out future exploration missions. For cryogenic propellants (oxygen, hydrogen, and methane), the technology needed for future long duration missions has yet to be demonstrated in space.

Future exploration missions can be greatly enhanced with the development of a robust, space or extraterrestrial based cryogenic fluid management, storage and distribution system. Extended presence of humans on the Moon and the exploration of Mars will depend on the long term storage and efficient use of cryogenic fluids for life support gases and high energy propellants. Developing a robust cryogenic fluid management system will allow humans to safely travel to and work on the Moon and Mars for extended periods. Storage of these fluids as a sub-critical liquid enables lightweight propellant tanks and distribution components. This then reduces the earth launch mass requirements for these components allowing more launch payload mass for critical scientific experiments. The basic CFM elements and functions of such a system include: storage, pressure control, fluid transfer, liquid acquisition fluid couplings, instrumentation, leak detection and quantity gauging. A combination of passive and active thermal control (refrigeration) could allow cryogenic propellants to be stored indefinitely with no losses, i.e., with zero boil-off (ZBO). A ZBO approach may be vital to missions requiring storage of propellants for durations of six months or more. Cryogenic propellant transfer operations allow the reuse of hardware already in orbit, thus reducing lift mass. Stages filled on-orbit can eliminate many of the crewed launch vehicle and structural mass and systems required to support and maintain cryogens on the launch pad. 
In response to this need NASA initiated several research programs to advance the state-of-the-art in CFM technology. This paper will report the current status and findings of these efforts. In the first part of the paper we will review the Exploration Systems Architecture Study (ref. 2) (ESAS) and their use of CFM technologies. In the second part of the paper we will discuss the results of technology efforts to date. These include the "In-Space Cryogenic Propellant Depot (ISCPD)," "Experimentation for the Maturation of Deep Space Cryogenic Refueling Technology (MDSCR)" including the follow-on "Cryogenic Propellant Operations Demonstrator" (CPOD) and the Zero Boil-Off Tank (ZBOT) flight experiments. All of these except for CPOD were initiated prior to the ESAS. The ISCPD and MDSCR projects have since been brought to a close. Although CPOD was not selected for the flight opportunity for which it was proposed the research team continues to advocate its benefit to the future exploration vehicle development and to review potential flight opportunities as they become available. The ZBOT experiment which has received some development funding continues although it has been decoupled from near term ESAS goals. Subsequent to the ISCPD and MDSCR projects the Propulsion and Cryogenic Advanced Development Project (PCAD) was initiated to support advanced development of CFM technology for the cryogenic propellant combinations recommended by the ESAS report. It is the intent of this paper to show the continuity of CFM technology research between these projects.

\section{Architecture Study}

Cryogenic propellant combinations are found throughout the baseline ESAS. Although several propellant changes have been proposed to the ESAS architecture since its release in December 2005 the cryogenic propellant combinations remain under discussion, so the baseline will be used as a representative example.

The Crew Exploration Vehicle (CEV) serves as the primary human transport of ESAS. ESAS sized the CEV for the human lunar return and used deltas to size the International Space Station (ISS) crew mission and Mars mission versions. The CEV command module is an Apollo like capsule which has no cryogens. Its propulsion is limited to Reaction Control Systems (RCS) only. The cryogenic propellant version of the CEV service module contains liquid oxygen and liquid methane. A pressure fed main engine provides propulsion for; rendezvous and docking with the lunar access module in earth orbit; contingency plane changes prior to lunar ascent; trans-earth injection; and self disposal. RCS thrusters provide on-orbit maneuvering. All thrusters are fed propellants from common tank sets of oxygen and methane. Helium pressurant bottles maintain the tank pressure. These bottles are thermally coupled to the methane tank to reduce the volume of the gaseous helium. Cryogenic fluid management systems for the CEV service module include passive storage multilayer insulation blankets for thermal control and thermodynamic vent systems for tank pressure control. Also, use of common propellant storage tanks for main engine and RCS engines will require a cryogenic liquid acquisition device (LAD) capable of feeding RCS thrusters in low gravity. Some of the later exploration missions may require stays at the ISS as long as six months possibly requiring augmentation of the passive storage systems with active refrigeration.

Although the first stage of the Crew Launch Vehicle (CLV) is a non-cryogenic solid rocket booster, it requires a large cryogenic upper stage to complete its mission. The baseline design uses a Space Shuttle Main Engine (SSME) and uses liquid oxygen and liquid hydrogen as its propellants. Cryogenic fluid management systems for this stage are similar to those used on current launch vehicles.

The Cargo Launch Vehicle (CaLV) uses a cryogenic liquid hydrogen-oxygen first stage core and upper earth departure stage of liquid hydrogen and liquid oxygen. The large mass and thrust of the CaLV mandate the use of high performance cryogenic propellants. Cryogenic systems for the first stage core are similar to the existing shuttle systems. The Earth Departure Stage (EDS) is another story. Approximately 60 percent of the EDS propellant is consumed in achieving a stable orbit. The remaining 40 percent must be stored until the CEV can be launched and rendezvous with the orbiting EDS. The EDS is restarted to propel the coupled CEV into lunar transit. The baseline study estimated the rendezvous time as a few weeks, but more recent analysis has suggested an even longer time of 95 days. Although Expendable Launch Vehicle (ELV) upper stages have demonstrated coasts as long as $9 \mathrm{hr}$, the EDS coast duration is several orders of magnitude beyond. Clearly using the boil-off venting to settle propellants as the Saturn rocket did is not viable for such an extended on-orbit time.

The Lunar Surface Access Module (LSAM) is a two stage vehicle, one stage for descent to the lunar surface and one stage for ascent from there. The LSAM ascent stage is similar to the CEV in being liquid oxygen/methane fueled, while the LSAM descent stage will be liquid oxygen/hydrogen like the EDS. The 
LSAM ascent stage's location near the end of the mission means that every kilogram saved here results in many kilograms saved on the CaLV weight. This makes the light weight of cryogenic propellants very attractive. CFM issues are similar to EDS except that the LSAM must wait with the EDS until the CEV arrives. This will increase the storage time required over that of CEV. In fact some of the later lunar base missions may require 6 months of storage (similar to the CEV at ISS) for the LSAM ascent stage.

In the technology assessment portion of the ESAS report the following cryogenic fluid management technologies were considered key: Liquid acquisition devices, passive thermal and pressure control, low gravity mass gauging, prototype pressure vessel demonstration, active thermal control, and CFM integrated system demonstration. It was also felt that RCS feed system testing with liquid oxygen and liquid methane would prove important.

\section{Technology Projects}

\section{A. In-Space Cryogenic Propellant Depot}

The In-Space Cryogenic Propellant Depot (ISCPD) project was designed to develop the technology required to manage and store large quantities of cryogenic propellants on-orbit. The ISCPD project encompassed a broad range of activities including architecture studies, CFD modeling, and ground testing of components and integrated systems. Components to be investigated included LADs, mass gauges, miniature leak detectors, cryocoolers, fluid umbilicals and fluid connectors. The goals of the ISCPD project are documented in Howell (ref. 3). Howell calls for CFM research in the area of liquid acquisition to develop a database for capillary screen wicking characteristics, surface tension data, and screen outflow performance to enable a depot capable of providing vapor free liquid down to a 2 percent residual level. He recommends development of a mass gauge with accuracy better than 5 percent. ISCPD mass gauging research and development has included work on optical, compression, and radio frequency gauges with the concept of down selecting to a best approach based on test results and systems analysis. Minimal or zeroloss (i.e., zero boil-off) cryogenic storage is required with goal of $<3$ percent boil-off per month. R\&D efforts in this area include development of cryogenic analysis tools, distribution technologies to support Broad Area Cooling (BAC) systems and more efficient long lived cryocoolers. A depot requires "leak free" transfer of cryogenic propellants. R\&D in this area included fluid umbilicals, connectors and miniature leak detectors. Integrated system ground testing with liquid oxygen and liquid hydrogen is recommended. Also recommended are technology flight demonstrations for CFM technologies requiring a low gravity environment.

The initial phase focused on technologies which could be investigated with ground testing. Strategies for the planned ground testing can found in Hastings (ref. 4). At the start of the study a database of previous depot concepts and studies was compiled (this will be summarized as a white paper in the MDSCR final report). As the results of the ESAS study began to unfold an agency shift to nearer term objectives led to the termination of the ISCPD project, but many of the CFM technology research efforts were folded into the follow-on PCAD project. These include the areas of heat entrapment by LADs, active cooling systems, as well as mass gauging with RF and optical systems. The test hardware being built up for ISCPD testing was quickly converted over to testing with liquid methane in PCAD. Although the ISCPD project was cancelled prior to the completion of the major test activities, it did produce a number of useful results detailed below. These results should be documented in ISCPD final report to be published shortly. Preliminary findings of ISCPD by technology area follow below.

\section{Liquid acquisition devices}

A series of bubble point measurements with $\mathrm{LO}_{2}$ on two representative screen samples was conducted and the fluid outflow characteristics of two sub-scale screen channel LAD's in $\mathrm{LO}_{2}$ was determined. Kudlac (ref. 5) presents these results. A fundamental heat entrapment test series with water was conducted. It concluded that, with water as the test fluid, capillary screen meshes of sizes typically anticipated for LAD applications represented barriers impervious to natural convection currents (ref. 6). This conclusion is yet to be verified with a cryogenic liquid. For the time being, it is recommended that cryogenic analysts treat capillary screen meshes as equivalent to solid barriers in static fluid temperature computations.

\section{Low gravity mass gauging}

Early evaluation of Compression Mass Gauging (CMG) technology indicated that the compression method in its current development stage with an oscillatory operating mode is limited to tank sizes on the 
order of $100 \mathrm{ft}^{3}$. Further development of the compression gauge, with both oscillatory and single-pulse modes, is still deemed highly worthwhile, however, for the ISCPD Project; it was decided to replace the CMG with a radio-frequency mass gauging (RF) technique as a more suitable concept for a depot (ref. 6).

For the RF mass gauging, a combined experimental and computer simulation effort developed to conduct test measurements of radio frequency tank resonance modes, which can be used to gauge the amount of cryogenic propellant in a tank. Using a handheld RF spectrum analyzer, laptop computer, coax cable, and a $4 \mathrm{~cm}$ long antenna in a small test dewar (1.6 $\mathrm{ft}^{3}$ capacity) experimental measurements were made of liquid oxygen at different fill levels. Computer simulation predictions of the four lowest electromagnetic eigenmodes as a function of liquid oxygen fill level were found to agree to within a few percent of the experimental measurements. Results of this effort can be found in Zimmerli (ref. 7).

Fundamental studies were conducted to better understand the principles of the OMG in low gravity. These included Monte Carlo modeling of the light absorption process and bench testing using a 10 in. tank filled with water and series of hollow glass spheres to represent low gravity configuration. Both efforts indicated sensitivity to wall reflectivity and low gravity bubble position, which needs to be considered to achieve mass gauging goals with an OMG. Preliminary ground testing using OMG techniques to gauge liquid nitrogen in a 5-liter stainless steel dewar proved inconclusive. Literature review indicated that a longer wavelength may be required to gauge liquid nitrogen than the ground test equipment could generate (ref. 6).

\section{Propellant tank thermal management}

Results of the CFD modeling of tank pressure control includes coorelation of $\mathrm{LH}_{2}$ thermodynamic vent system (TVS) spray bar test results with the MSFC Mutipurpose Hydrogen Test Bed (MHTB), addition of a helium noncondensable model to the base model and coorelation with Saturn IVB flight data (ref. 8). Grayson (ref. 9) compares CFD analysis against the Saturn IV flight test data to predict on-orbit pressure rise rates. To aid in understanding the effects of liquid hydrogen pressurized with non-condensable gaseous helium, testing was conducted in the existing MHTB tank (ref. 6). Prior work with MHTB (refs. 10 to 12) has included autogenously pressurized liquid hydrogen as well as liquid nitrogen pressurized both autogenously and gaseous helium.

A literature search was performed for advanced concepts that would be used to efficiently integrate cryocoolers with propellant tanks. Starting from existing cryogenic thermal modeling tools (ref. 13) the Cryogenic Analysis Tool (CAT) was enhanced (CAT+) specifically for a depot application. Using CAT+ and radiation modeling the thermal management elements that were required for the Depot Test Bed were identified and specified. Several configurations were analyzed in detail including; A metallic shield cooled by helium gas at $90 \mathrm{~K}$ (also known as Broad Area Cooling) including augmentation with $20 \mathrm{~K}$ cryocooler to achieve Zero Boil-off; and a metallic shield cooled conductively by the oxygen tank and surrounding the hydrogen tank. A Regenerator Test Facility was designed and fabricated to develop technology for longterm storage of liquid hydrogen (ref. 6).

\section{Integrated system ground testing}

An initial design for a depot test bed was completed (ref. 6).

5. "Leak free" transfer of cryogenic propellants

Progress in this area included review of the literature of cryogenic disconnects and designs for lunar surface systems. Work from this area has been moved to the Consumable's Transfer task of the Exploration Systems Mission Directorate's supportability project. Notardanoto (ref. 24) describes progress on this task.

\section{B. Experimentation for the Maturation of Deep Space Cryogenic Refueling Technology}

The Experimentation for the Maturation of Deep Space Cryogenic Refueling Technology (MDSCR) study identified cryogenic fluid management technologies that require low gravity flight experiments to bring to Technology Readiness Level (TRL) 5-6; examined many possible flight experiment options; and developed near-term low-cost flight experiment concepts to mature the core technologies. Goals of the study are documented in Chato (ref. 14). Chato found key CFM technologies to include passive storage, active storage, pressure control, mass gauging, liquid acquisition, and fluid transfer, table 1 summarizes the core technologies of cryogenic propellant operations identified by Chato and their need for low gravity testing. A total of twenty-five white papers were prepared by members of the project team in the course of this study. An overview of the white papers is found in Chato (ref. 15). A NASA Technical Paper with the 
complete white papers is currently in the final stages of preparation and should be published shortly. The team reviewed the six white papers that provided information on new or novel concepts of experiments to pursue and ranked them on the basis of technical need, cost, return on investment and flight platform.

TABLE 1.-FLIGHT TESTING REQUIREMENTS OF CRYOGENIC PROPELLANT OPERATIONS

\begin{tabular}{|c|c|c|c|c|}
\hline $\begin{array}{l}\text { CFM } \\
\text { technology } \\
\text { element }\end{array}$ & $\begin{array}{l}\text { Current } \\
\text { TRL }\end{array}$ & $\begin{array}{c}\text { Past 1-g } \\
\text { accomplishments }\end{array}$ & $\begin{array}{l}\text { Low-g } \\
\text { issues }\end{array}$ & $\begin{array}{l}\text { Flight } \\
\text { testing }\end{array}$ \\
\hline $\begin{array}{l}\text { Passive } \\
\text { storage- }\end{array}$ & 5 & $\begin{array}{l}3 \% \text { loss } / \text { month demonstrated with } \\
\text { large-scale } \mathrm{LH}_{2} \text { test }\end{array}$ & $\begin{array}{l}\text { Low g thermal stratification } \\
\text { effects unknown }\end{array}$ & $\begin{array}{l}\text { Highly } \\
\text { desirable }\end{array}$ \\
\hline $\begin{array}{l}\text { Active } \\
\text { storage } \\
\text { (zero } \\
\text { boil-off) }\end{array}$ & $\begin{array}{l}4 \mathrm{LO}_{2} / \\
\mathrm{CH}_{4} \\
3 \mathrm{LH}_{2}\end{array}$ & $\begin{array}{l}\text { Subscale demo with } \mathrm{LN}_{2} \text { and } 10 \mathrm{~W} \text { at } \\
97 \mathrm{~K} \text { cryocooler } \\
\text { Large scale demo with commercial } \\
\text { cryocooler }\end{array}$ & $\begin{array}{l}\text { Low g thermal stratification } \\
\text { effects unknown }\end{array}$ & $\begin{array}{l}\text { Highly } \\
\text { desirable }\end{array}$ \\
\hline $\begin{array}{l}\text { Pressure } \\
\text { control }\end{array}$ & 4 & $\begin{array}{l}\text { Large scale demo of thermodynamic } \\
\text { vent system (TVS) with spray bar } \\
\text { Subscale test of TVS with axial jet } \\
\text { mixer }\end{array}$ & $\begin{array}{l}\text { Low g heat transfer and fluid } \\
\text { dynamics effects mixing, } \\
\text { destratification and cycle } \\
\text { rate }\end{array}$ & $\begin{array}{l}\text { Highly } \\
\text { desirable }\end{array}$ \\
\hline $\begin{array}{l}\text { Mass } \\
\text { gauging }\end{array}$ & 3 & $\begin{array}{l}\text { Component testing with simulant } \\
\text { fluids, } \\
\mathrm{LN}_{2} \text { and limited } \mathrm{LH}_{2}\end{array}$ & $\begin{array}{l}\text { Some concepts strongly } \\
\text { effected by low g heat } \\
\text { transfer and fluid behavior }\end{array}$ & $\begin{array}{l}\text { Highly } \\
\text { desirable }\end{array}$ \\
\hline $\begin{array}{l}\text { Liquid } \\
\text { acquisition }\end{array}$ & 3 & $\begin{array}{l}\text { Bubble point testing with } \mathrm{LN}_{2} \\
\text { Historical data (1960s) }\end{array}$ & $\begin{array}{l}\text { Low g heat transfer } \\
\text { significantly effect LAD } \\
\text { performance }\end{array}$ & Required \\
\hline $\begin{array}{l}\text { Fluid } \\
\text { transfer }\end{array}$ & 3 & $\begin{array}{l}\text { Subscale demo of chill and no-vent fill } \\
\text { testing }\end{array}$ & $\begin{array}{l}\text { Transfer operation strongly } \\
\text { effected by low g }\end{array}$ & Required \\
\hline
\end{tabular}

Although the MDSCR study ended prematurely due to changing NASA priorities, it will leave a legacy of ideas for future research. A number of the white papers document historical experiments and approaches. These should prove valuable to future researchers. The white papers that highlight new and novel concepts will serve as a head start for preparing experiments in the future. Ideas from this effort are already being adapted for use in the PCAD program. Several of the new and novel concept white papers have been expanded into full length papers these include Salka (ref. 15) and Kutter (ref. 16). As NASA focus' moves on to Lunar and Mars exploration the results of MDSCR will provide a valuable reference for the design of the flight experiments required for those challenging missions.

\section{Cryogenic Propellant Operations Demonstrator}

The top rated MDSCR experiment concept was Centaur Test Bed (CTB). It proposed a small cryogenic experiment tank attached to the aft end of an existing launch vehicle upper stage (ref. 15). The Cryogenic Propellant Operations Demonstrator (CPOD) payload was developed from CTB to respond the Exploration Systems Mission Directorate's Robotic Lunar Exploration Program (RLEP) Secondary Payload Mission call for proposals. Figure 1 shows an artist's concept of this tank and valve panel for the experiment. The proposed design attaches to existing hard points on the upper stage and is isolated from the stage propulsion by pyrotechnic valves until after the primary upper stage mission is complete. A highly reliable flight qualified redundant pyrotechnic isolation valve will be installed by the launch vehicle manufacturer into the existing propellant feed line. As such the experiment can be integrated as a secondary payload on any launch with excess payload capacity with minimal impact to the primary payload.

Figure 2 shows an artists concept of the CPOD receiver tank and a cut-away to reveal the experiment hardware. Shown in the cut-away are a screened LAD with four channels and a compact heat exchanger and mixer motor assembly similar to those used for TVS ground test.

A review of technologies versus the proposed experiment capabilities led to an initial selection of technologies to pursue. Good coverage is provided for all MDSCR cryogenic technologies (table 1) with the exception of active storage (the development of a flight-rated cryocooler for liquid hydrogen storage would add significantly to the cost and schedule risk of this proposal). Descriptions of the CPOD approach to technology follow. 


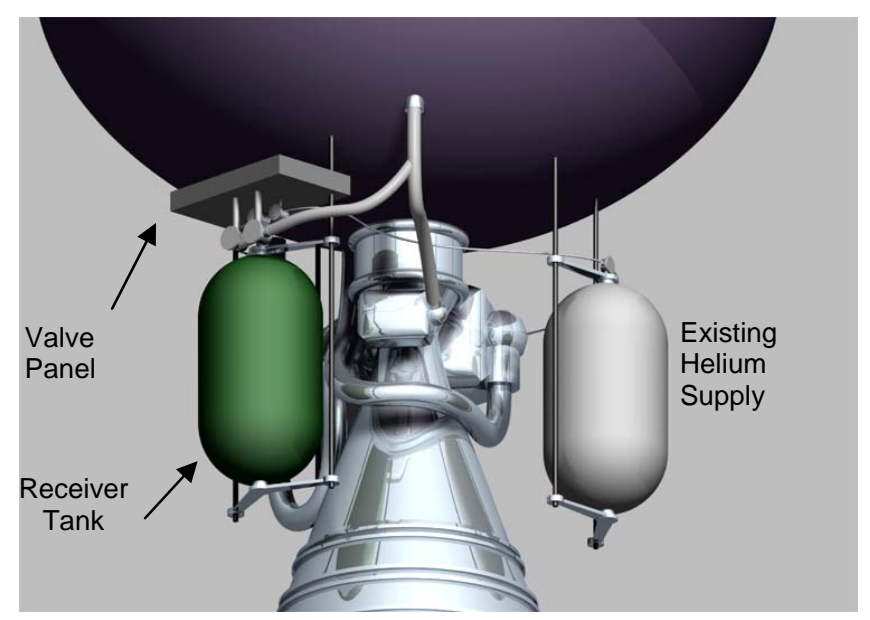

Figure 1.-Artist concept of CPOD based on the LockheedMartin Centaur Test Bed (CTB) concept.

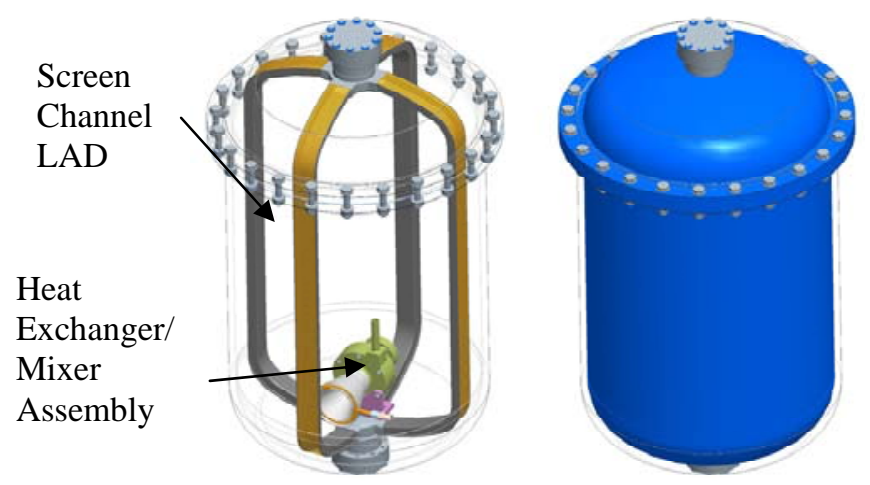

Figure 2.-CPOD receiver tank (right) and cut-away (left) to reveal internal experiment hardware including mixer assembly and LAD channels.

\section{Passive storage}

CPOD will demonstrate the thermal stratification of a cryogenic fluid in low-gravity. Heaters or warm helium pressurant will be used to accelerate the stratification process so that it can be demonstrated in a single day.

\section{Pressure control}

CPOD will carry a thermodynamic vent system and mixer motor to demonstrate their operation in low gravity. Heaters or warm helium pressurant will be used to accelerate the stratification process so that pressure control can be demonstrated in a single day.

\section{Mass gauging}

CPOD plans to demonstrate the mass gauge developed by the PCAD project. CPOD was designed assuming an RF mass gauge but other approaches could be accommodated.

\section{Liquid acquisition}

CPOD will include a state-of-the-art LAD design. It will demonstrate the filling of LADs on orbit, and the minimum propellant residuals obtainable with bubble-free outflow for cryogens in low gravity.

\section{Fluid transfer}

CPOD will demonstrate a complete chilldown and no-vent fill of a cryogenic tank in low gravity. Additional parametric studies on the filling process will be conducted until all propellant is expended. 


\section{Zero Boil-Off Technology Experiment}

This experiment involves performing a small scale ISS experiment to study tank pressurization and pressure control in microgravity. The ZBOT experiment was the only concept studied by MDSCR capable of investigating the thermal stratification issues of long term storage. The approach was to construct a detailed CFD model and validate it with small and large scale ground test data. Then small scale on-orbit data would be used to assess the changes between small ground test and small scale flight test, the model re-validated for the small scale flight data and then used to predict large scale flight performance. Barsi (ref. 17) documents the preliminary results of modeling and ground test efforts. Barsi and Kassemi (ref. 18) show an early ZBOT experiment design and present model predictions for this design. Figure 3 shows the test chamber for this early design. The ZBOT experiment consists of a test tank filled with an inert fluorocarbon simulant liquid filled with fine particles. A vacuum jacket provides a thermally insulated environment for the test tank. Heaters on the tank wall (not shown) will be used to stratify the tank at the start of the test. A pump will be used to withdraw fluid from a liquid acquisition device and re-inject it back into the tank via the axial jet nozzle at the bottom of the tank. Fluid cooling can be provided either in the pump flow loop or via a fluid filled cold finger internal to the tank. Laser diagnostics will be used to measure the resultant fluid motions accurately using particle imaging velocimetry. This will provide a high quality database of low gravity fluid motions which will be used to validate the CFD model.

Although not the highest rated experiment in the MSDCR review, development of the Zero Boil-Off Technology (ZBOT) experiment has continued. Its low cost and use of the ISS facility have led to continued interest in its development. The computer modeling of low-g fluid behavior that has been developed as a part of the ZBOT has served as a springboard to support modeling of other cryogenic fluid management issues important to the Exploration mission (see PCAD below). Validation of low gravity

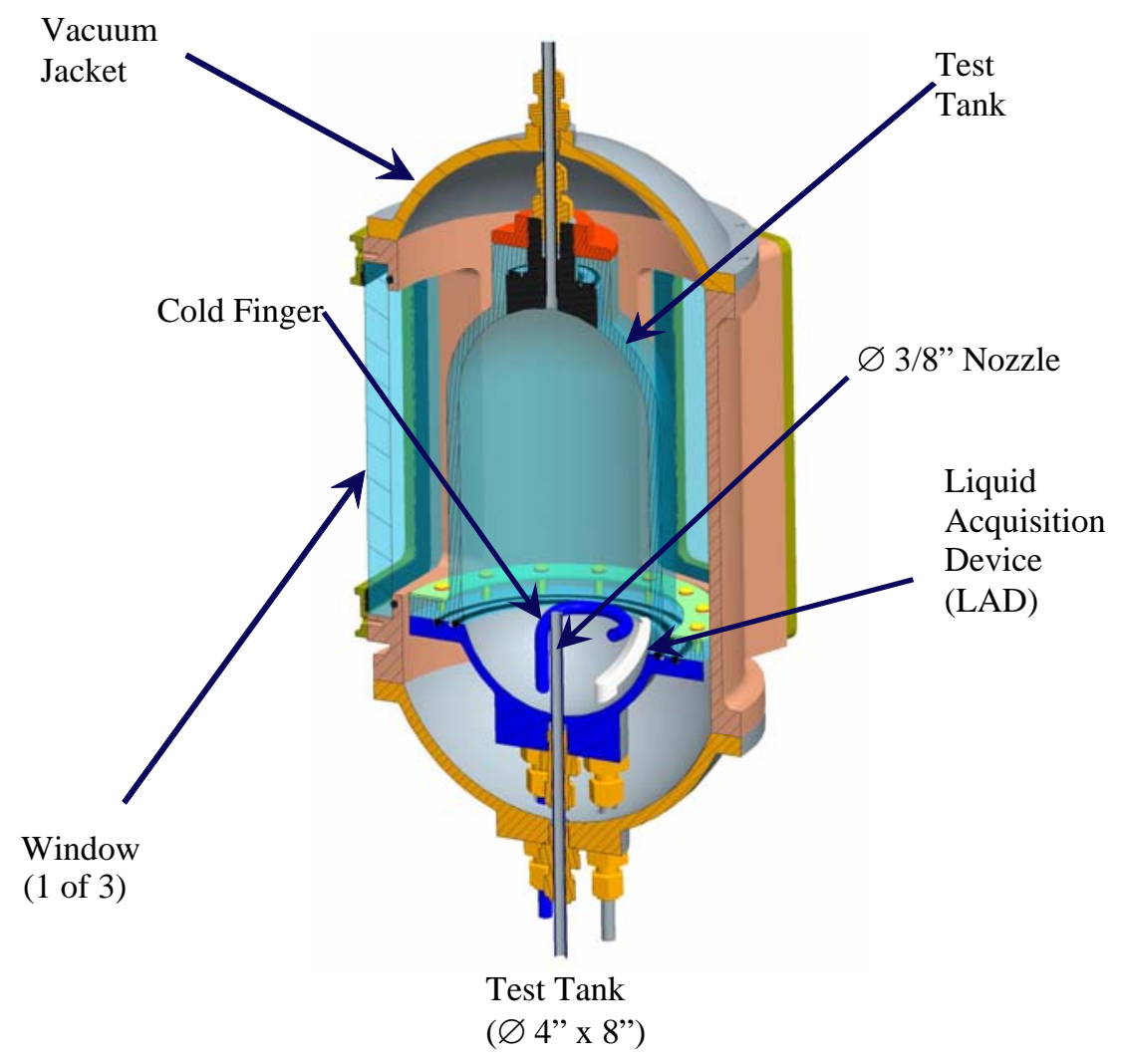

Figure 3._ZBOT ISS hardware design details cutaway of test chamber. 
fluid models will be greatly assisted by data obtained from the ZBOT flight experiment. To address the MDSCR concerns about ZBOT the experiment was peer reviewed in the fall of 2006. The review panel of NASA and Industry experts agreed that ZBOT should continue but recommended reducing the experimental complexity of the first flight so that it could be accomplished more quickly. They also recommended adding additional flights to capture test objectives deferred from the first flight. Results of the peer review are being currently addressed by the ZBOT team. Work is underway to include both an intense modeling effort and extensive scaling analyses.

\section{E. Propulsion and Cryogenic Advanced Development}

In response to the ESAS report the Propulsion and Cryogenic Advanced Development (PCAD) project was developed to mature the CFM technology recommended in the report. Note: PCAD also includes engine development work for liquid oxygen/methane and liquid oxygen/hydrogen engines, but this paper will focus on its CFM aspects. The scope of the CFM task is storage, acquisition and distribution of cryogenic propellants. The objectives are: to reduce development risk of advanced technology cryogenic propellant systems; and to increase Technology Readiness Levels (TRL) of CFM subsystems through one-g testing and analytical model development. Although PCAD encompasses all green cryogenic propellants including liquid hydrogen for 2006 the project was focused on developing technologies in liquid oxygen and liquid methane as technologies for these propellants are less mature (ref. 22).

\section{Thermal control}

Active cooling (refrigeration) is a propellant thermal control, long duration storage option for cryogenically fueled exploration vehicles if passive thermal control (MLI only) loads are higher than predicted or densified propellants are not used. 2006 activities have included modeling tool development and a BAC system design using a $90 \mathrm{~K}$ cryocooler integrated with a helium circulator imbedded in the MLI of a $\mathrm{LH}_{2}$ propellant tank to significantly reduce the $\mathrm{LH}_{2}$ boil-off loss. Testing is planned for 2007 using the ISCPD developed Regenerator Test Facility both for regenerators and to study issues related to recirculating helium for BAC (ref. 23).

\section{Pressure control}

Controlling cryogenic propellant tank pressure in low gravity will require use of a thermodynamic vent system. A TVS typically consists of a pump for circulation and mixing; a Joule-Thomson (JT) expansion device and heat exchanger to remove heat, and a vent line. In 2006 PCAD demonstrated JT expansion device performance in both liquid oxygen and liquid methane (prior work exists for JT in hydrogen). Ground testing in the MHTB is examining large scale liquid methane handling and performance of the existing spray bar system to maintain tank pressure control for typical LEO heat loads. For 2007 a $\mathrm{LO}_{2}$ TVS component test series is planned (ref. 23).

\section{Liquid acquisition}

Providing vapor free cryogenic propellants to in-space propulsion systems at expulsion efficiency greater than 98 percent without settling the propellants is the PCAD objective for this technology. In 2006 data was gathered on the bubble point of two representative fine mesh screens using liquid methane at both saturated and subcooled fluid conditions. For 2007, an improved optics system is now being installed for additional bubble point testing for liquid methane, liquid hydrogen and liquid oxygen (ref. 23).

\section{Mass gauging}

In propellant gauging the goal for the exploration vehicles is $<3$ percent uncertainty measurement in low/omni-gravity. Recent ground tests have demonstrated the feasibility of the PVT method by using liquid nitrogen (ref. 19) as a simulant for liquid oxygen and liquid methane. However, measured uncertainty is close to the outer limit of the exploration vehicle goal. For 2007, PVT testing with liquid oxygen and, liquid methane is planned. Analysis (ref. 20) has shown maintaining PVT uncertainty is challenging for liquid hydrogen systems, so alternate approaches are under development. In 2006 a small scale in-house demonstration of the Radio Frequency (RF) concept feasibility was completed with $\mathrm{LO}_{2}$. For 2007, larger scale testing of both RF and OMG in liquid oxygen is planned. The testing for these concepts will use a highly accurate weighing system to provide a standard against which the uncertainly can be measured (ref. 23). 


\section{Propellant feed line conditioning}

Maintaining vapor-free liquid propellant between the tank outlet and RCS engine inlets is a significant technology challenge. A passive TVS (similar to the tank pressure control TVS but without the pump) attached to feed line can adsorb much of the parasitic heat and keep the lines cooled. Testing on this concept began in 2006 at JSC with liquid nitrogen and White Sands Test Facility with liquid oxygen and methane. Testing is expected to continue through 2007 (ref. 23).

\section{Concluding Remarks}

Our review of the ESAS indicates the importance of cryogenic fluid management. The study proposes cryogenic fluid management technologies for the CEV, the EDS and LSAM. Key technologies include liquid acquisition devices, passive thermal and pressure control, low gravity mass gauging, prototype pressure vessel demonstration, active thermal control, RCS feed system testing, and Cryogenic Fluid Management integrated system demonstration. The In-Space Cryogenic Propellant Depot project examined the technologies of liquid acquisition, low-gravity mass gauging, Propellant tank thermal management (which included passive and active storage, as well as pressure control), integrated system test, and fluid transfer. ISCP produced advancements in these technologies including: research papers in liquid acquisition of oxygen, computational modeling of low gravity pressure control, and low-gravity RF mass gauging and soon to be published work on BAC. The MDSCR project examined flight experiment approaches for cryogenic technologies of passive storage, active storage, pressure control, mass gauging, liquid acquisition and fluid transfer. The CPOD project further develops a flight experiment concept first proposed in MDSCR. It proposes a small cryogenic tank capable of flying as a secondary payload on a cryogenic upper stage. CPOD is capable of investigating all MSDCR technologies except active storage. The ZBOT project, although on-going prior to MSDCR, has been improved by MDSCR recommendations. It proposes a small space station research experiment to investigate the technologies of active storage and pressure control. Both ISCPD project and the MDSCR project proved valuable in providing a quick start the PCAD project. Key technologies for PCAD include: thermal control (active storage), pressure control, liquid acquisition, mass gauging, and propellant feed line conditioning. Although PCAD encompasses all green cryogenic propellants including liquid hydrogen for 2006 the project was focused on developing technologies in liquid oxygen and liquid methane as technologies for these propellants are less mature.

We have reviewed NASA exploration architecture and seen the importance of CFM in its goals. We have seen the advancement of CFM technology in the ISCPD and MDSCR projects. We have seen a continuation of the CFM technology approaches from ISCPD and MDSCR projects into the current CPOD, ZBOT and PCAD projects. The current CEV design is moving away from cryogenic systems due to the long lead time associated with methane engines. However CFM remains a key technology for later exploration missions. The EDS remains a large cryogenic user and the current LSAM ascent and descent stages require the use of cryogenically fueled propulsion systems demanding the further advanced development of CFM technology.

\section{References}

1. Bush, G.W. “A Renewed Spirit of Discovery: The Presidents Vision for U.S. Space Exploration,” January 2004.

2. Anonymous "NASA's Exploration Systems Architecture Study Final Report” NASA TM 2005214062, November 2005.

3. Howell, J.T., J.C. Mankins, J.C. Fikes “In-Space Cryogenic Propellant Depot stepping stone” Acta Astronautica 59, 2006.

4. Hastings, L., et. al., "Marshall Space Flight Center In-Space Cryogenic Fluid Management Program Overview” AIAA-2005-3561, July, 2005.

5. Kudlac, M., J. Jurns, “Screen Channel Liquid Acquisition Devices for Liquid Oxygen” AIAA-20065054, July 2006.

6. Howell, J.T. et. al. "In-Space Cryogenic Propellant Depot Final Report,” in preparation for publication as NASA TM.

7. Zimmerli, G.A. et. al. "Radio Frequency Mass Gauging of Propellants," AIAA-2007-1198, January 2007.

8. Anonymous, "Evaluation of AS-203 Low-Gravity Orbital Experiment,” NASA CR 94045, 13 January 1967. 
9. Grayson G., et. al. “Cryogenic Tank Modeling for the Saturn AS-203 Experiment” AIAA-2006-5258, July, 2006.

10. Hastings, L. et. al. "Spray Bar Zero Gravity Vent System for On-Orbit Liquid Hydrogen Storage,” NASA/TM-2003-212926; October 2003.

11. Leon J. Hastings, James J. Martin "Testing of a Spray Bar Zero Gravity Cryogenic Vent System for Upper Stages,” 35th AIAA/ASME/SAE/ASEE Joint Propulsion Conference and Exhibit; Los Angeles, CA; AIAA 99-2175; June 20-24, 1999.

12. Flachbart, Robin H. et. al. "Testing of a Spray-Bar Thermodynamic Vent System in Liquid Nitrogen” Cryogenic Engineering Conference; Keystone CO; August 29-September 2, 2005.

13. Plachta, D., and Kittel, P., An Updated Zero Boil-Off Cryogenic Propellant Storage Analysis Applied to Upper Stages or Depots in an LEO Environment NASA/TM—2003-211691, June 2003.

14. Chato D.J., "Flight Development for Cryogenic Fluid Management in Support of Exploration Missions" AIAA-2006-0940 January, 2006.

15. Chato, D.J., "Low Gravity Issues of Deep Space Refueling,” AIAA-2005-1148, January 2005.

16. Sakla S., B. Kutter, and J. Wall, “Centaur Test Bed (CTB) for Cryogenic Fluid Management” AIAA2006-4603, July, 2006.

17. Kutter B., et. al. “Settled Cryogenic Propellant Transfer” AIAA-2006-4436 July 2006.

18. Barsi, S., et. al. "A Tank Self-Pressurization Experiment Using a Model Fluid in Normal Gravity,” AIAA-2005-1143, January, 2005.

19. Barsi, S., M. Kassemi, “A Numerical Study of Tank Pressure Control in Reduced Gravity,” AIAA2006-936, January, 2006.

20. Van Dresar, N., "PVT Gauging with Liquid Nitrogen,” Cryogenics 46 pp. 118-125, 2006.

21. Van Dresar, N., "An Uncertainty Analysis of the PVT Gauging Method Applied to Sub-Critical Cryogenic Propellant Tanks,” Cryogenics 44 pp. 515-523, 2004.

22. Motil, S., Meyer, M., Tucker, S. "Cryogenic Fluid Technologies for Advanced Green Propulsion Systems” AIAA-2007-343, January 2007.

23. Anonymous "Propulsion and Cryogenic Advanced Development Cryogenic Fluid Management Schedule,” Propulsion and Cryogenic Advanced Development Project Office Records, Cleveland, OH (unpublished).

24. Notardanoto, W. "Development of Consumable Transfer Systems for Sustainable Lunar Exploration," AIAA-2007-0957, January 2007. 


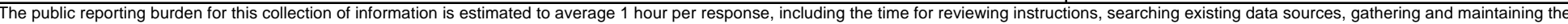

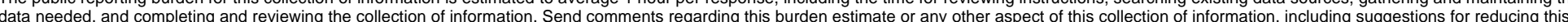

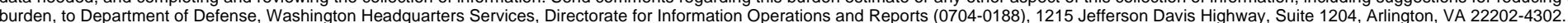

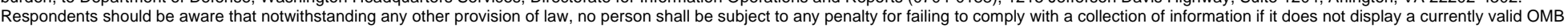
control number.

PLEASE DO NOT RETURN YOUR FORM TO THE ABOVE ADDRESS.

\begin{tabular}{l|l|l} 
1. REPORT DATE (DD-MM- $Y Y Y Y)$ & 2. REPORT TYPE & 3. DATES COVERED (FrOm - To)
\end{tabular}

01-09-2007

Technical Memorandum

\section{TITLE AND SUBTITLE}

Cryogenic Technology Development for Exploration Missions

5a. CONTRACT NUMBER

5b. GRANT NUMBER

5c. PROGRAM ELEMENT NUMBER

6. AUTHOR(S)

Chato, David, J.

\section{5d. PROJECT NUMBER}

5e. TASK NUMBER

5f. WORK UNIT NUMBER

WBS 253225.04.01.02.04.01.03

\section{PERFORMING ORGANIZATION NAME(S) AND ADDRESS(ES)}

National Aeronautics and Space Administration

John H. Glenn Research Center at Lewis Field

Cleveland, Ohio 44135-3191

9. SPONSORING/MONITORING AGENCY NAME(S) AND ADDRESS(ES)

National Aeronautics and Space Administration

Washington, DC 20546-0001

\section{PERFORMING ORGANIZATION \\ REPORT NUMBER \\ E-16016}

\section{DISTRIBUTIONIAVAILABILITY STATEMENT}

Unclassified-Unlimited

Subject Category: 20

Available electronically at http://gltrs.grc.nasa.gov

This publication is available from the NASA Center for AeroSpace Information, 301-621-0390

\section{SUPPLEMENTARY NOTES}

\section{ABSTRACT}

This paper reports the status and findings of different cryogenic technology research projects in support of the President's Vision for Space Exploration. The exploration systems architecture study is reviewed for cryogenic fluid management needs. It is shown that the exploration architecture is reliant on the cryogenic propellants of liquid hydrogen, liquid oxygen and liquid methane. Needs identified include: the key technologies of liquid acquisition devices, passive thermal and pressure control, low gravity mass gauging, prototype pressure vessel demonstration, active thermal control; as well as feed system testing, and Cryogenic Fluid Management integrated system demonstration. Then five NASA technology projects are reviewed to show how these needs are being addressed by technology research. Projects reviewed include: In-Space Cryogenic Propellant Depot; Experimentation for the Maturation of Deep Space Cryogenic Refueling Technology; Cryogenic Propellant Operations Demonstrator; Zero Boil-Off Technology Experiment; and Propulsion and Cryogenic Advanced Development. Advances are found in the areas of liquid acquisition of liquid oxygen, mass gauging of liquid oxygen via radio frequency techniques, computational modeling of thermal and pressure control, broad area cooling thermal control strategies, flight experiments for resolving low gravity issues of cryogenic fluid management. Promising results are also seen for Joule-Thomson pressure control devices in liquid oxygen and liquid methane and liquid acquisition of methane, although these findings are still preliminary.

\section{SUBJECT TERMS}

Cryogenics; Launch vehicles; Microgravity

\begin{tabular}{|l|l|l|l|}
\hline \multicolumn{2}{|l|}{ 16. SECURITY CLASSIFICATION OF: } & $\begin{array}{l}\text { 17. LIMITATION OF } \\
\text { ABSTRACT }\end{array}$ \\
\begin{tabular}{|l|l|l|} 
a. REPORT \\
U
\end{tabular} & $\begin{array}{l}\text { b. ABSTRACT } \\
\text { U }\end{array}$ & $\begin{array}{l}\text { c. THIS } \\
\text { PAGE } \\
\text { U }\end{array}$ & UU \\
\hline
\end{tabular}

18. NUMBER
OF
PAGES
16

19a. NAME OF RESPONSIBLE PERSON STI Help Desk (email:help@sti.nasa.gov) 19b. TELEPHONE NUMBER (include area code) 301-621-0390 

